\title{
Multiband Microstrip Antenna Using Modified Pi-Shape Slot on Ground Plane
}

\author{
Poonam A. Kadam ${ }^{\text {a }}$ Amit A. Deshmukh \\ ${ }^{a}$ Research Scholar, EXTC Dept., SVKM's D. J. Sanghvi College of Engineering, Mumbai 400056, India \\ ${ }^{b}$ Professor \& Head, EXTC Dept., SVKM's D. J. Sanghvi College of Engineering, Mumbai 400056, India
}

Received: 24 September 2018; Accepted: 18 October 2018; Published: 08 January 2019

\begin{abstract}
This paper proposes a multiband microstrip antenna with modified pi-shape slot cut on the ground plane for wireless applications. Complete modal analysis and design process of the proposed antenna is demonstrated explaining the modes contributing to achieve the bands. By placing the modified pi-slot in the appropriate position on the ground plane, it tunes $\mathrm{TM}_{10}, \mathrm{TM}_{12}, \mathrm{TM}_{02}$ and $\mathrm{TM}_{20}$ and $\mathrm{TM}_{22}$ mode frequencies with respect to the fundamental mode frequency and thus realizes four band response which includes one broadband response having $164 \mathrm{MHz}(6.5 \%)$ bandwidth. The bandwidth in the other bands are in the range of $6 \mathrm{MHz}-30 \mathrm{MHz}$. The surface currents at these modes are also altered to yield broadside radiation pattern. Suspended version of this antenna is also proposed that offers triple bands and improved broadside gain of around $4 \mathrm{dBi}$ at the broadband besides $2.5 \mathrm{dBi}$ and $1 \mathrm{dBi}$ gain at other two modes. The proposed antenna saves 56\% area with respect to the equivalent un-slotted microstrip antenna.
\end{abstract}

Index Terms: Compact microstrip antenna, Defected ground plane structure, Multiband microstrip antenna, Modified Pi-shape slot

(C) 2019 Published by MECS Publisher. Selection and/or peer review under responsibility of the Research Association of Modern Education and Computer Science

\section{Introduction}

The ever-increasing demands of multiple frequencies for wireless devices can be adeptly addressed by means of compact multiband microstrip antennas (MSA) [1]. Various techniques for realizing broadband and multiband antennas is reported in literature that includes gap coupled configurations, antennas with stubs at radiating or non-radiating edges of the patch or antennas having slots at the appropriate positions on the patch

* Corresponding author. Tel.: +91-022-42335000 ext. 1227

E-mail address: poonamkadam80@gmail.com 
[2 - 5]. Also many researchers have discussed compact antenna realization by incorporating slots on the radiating patch [6 - 9]. Recently lots of emphasis is being given to antennas having defected ground structures (DGS). In DGS the slots, which are more commonly called defects are introduced purposely in the ground plane to meet the antenna performances. Significant amount of antenna size reduction due to ground slots is reported in papers [10 - 14]. The multiband / broadband antennas are realized by placing the higher order modes optimally close to the fundamental mode frequency such that the bands / loop lie within VSWR $=2$ circle. The shape and position of the defect is chosen based on the resonant frequencies targeted for achieving multiband or broadband response [15]. Defected ground structures have various applications in microwave device design such as filters, power amplifiers, microwave oscillators etc. However they are gaining much popularity in multiband / broadband microstrip antenna design. The defects on the ground plane perturbs the surface current distribution of the patch and thus results in frequency reduction. Despite of extensive literature on multiband DGS microstrip antenna design, only a small fraction of the papers elaborates on the design process of these antenna configurations. Also modal analysis which is essential to understand in order to know antenna behavior on incorporating slots in ground plane is missing in the reported papers.

In this paper multiband DGS microstrip antenna is designed by placing modified pi-slot on its ground plane. The higher order mode frequencies are brought down with respect to the fundamental mode frequency such that they give multiband or broadband response. The complete modal analysis of this antenna is covered in this paper. Also suspended configuration of pi-slot DGS antenna is designed to exhibit large gain of up to $4 \mathrm{dBi}$. Four resonant peaks are observed which are due to $\mathrm{TM}_{10}, \mathrm{TM}_{12}, \mathrm{TM}_{20}$ and $\mathrm{TM}_{22}$ modes respectively at 1140, 1530, 1640 and $1992 \mathrm{MHz}$ frequencies. $\mathrm{TM}_{12}, \mathrm{TM}_{20}$ modes are optimally spaced to give broad band response. Tripple band response is obtained with bandwidth of $18 \mathrm{MHz}(1.7 \%), 158 \mathrm{MHz}(10 \%)$ and $30 \mathrm{MHz}(1.6 \%)$. The radiation pattern observed at each of the resonant modes are broadside. The gain of the proposed antenna is calculated using two-antenna gain method. The gain obtained at these bands are $2.5 \mathrm{dBi}, 4 \mathrm{dBi}$ and $1 \mathrm{dBi}$ respectively. Since the fundamental mode frequency is brought down to $1.14 \mathrm{GHz}$ from $1.5 \mathrm{GHz}$, significant reduction in area is achieved. The proposed antenna is simulated using IE3D software followed by fabrication. The antennas are fabricated using glass epoxy substrate having dielectric constant of 4.3 and $\tan \delta=0.02$. The impedance measurement was carried out using ZVH-8 vector network analyzer and the radiation pattern was measured using spectrum analyzer FSC 6. Simulated results are compared with the measured data which shows close matching between them.

\section{Design of Modified Pi-slot Defected Ground MSA}

A compact multiband antenna consisting of three dielectric layers is projected in the paper. This section covers the design approach along with the modal analysis of the antenna. The design progressed with the study of a rectangular patch antenna of dimension chosen as $46 \mathrm{~mm}$ x $60 \mathrm{~mm}$ such that it operates at fundamental mode frequency of $1500 \mathrm{MHz}$. The ground dimension is $10 \mathrm{~mm}$ more than the patch edge on each side $(66 \mathrm{~mm}$ x $80 \mathrm{~mm}$ ). The feed is located at $16 \mathrm{~mm}$ left to the center point along the patch length. The antenna of this dimension with the given feed location is fabricated using the glass epoxy substrate having dielectric constant of 4.3 and loss tangent 0.02 operates at $\mathrm{TM}_{10}$ fundamental mode frequency of $1500 \mathrm{MHz}$. The simulations are carried out using IE3D software and the resonance plot displaying various excited resonant peaks is shown in the Fig. 1 (b). The simulation shows fundamental $\mathrm{TM}_{10}$ mode resonant peak at $1530 \mathrm{MHz}$ frequency. The second resonant mode is observed at $2300 \mathrm{MHz}$ which corresponds to $\mathrm{TM}_{02}$. Third and fourth peaks are due to $\mathrm{TM}_{12}$ mode and $\mathrm{TM}_{20}$ modes which are observed at $2500 \mathrm{MHz}$ and $3030 \mathrm{MHz}$ frequencies respectively. 


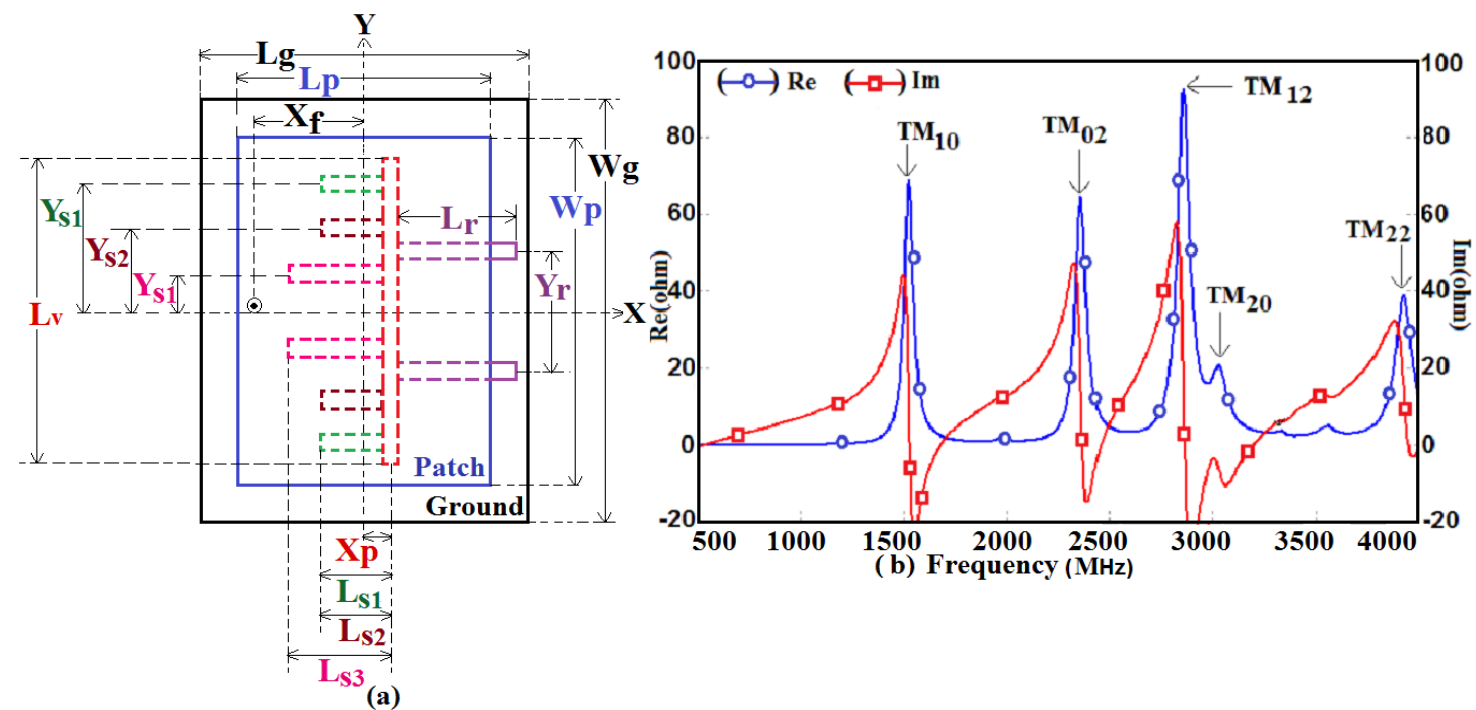

Fig.1. (a) DGS RMSA with modified pi-slot (b) resonance plot (Real and Imaginary) of RMSA without slots

In order to achieve compactness, a vertical slot is etched at the center along the patch width as shown in Fig. 1 (a). The increase in length of this vertical slot $\left(\mathrm{L}_{\mathrm{v}}\right)$ shifts the fundamental mode frequency significantly towards the lower value as the slot length is orthogonal to the surface current direction at this mode. On the other hand this slot does not affect the next higher order orthogonal mode frequency $\mathrm{TM}_{02}$ since the surface current at this mode is along with the slot. However slight deviation in the $\mathrm{TM}_{12}$ mode is seen confirming reduction in its frequency. This effect is studied through simulation for varying slot length and is shown in Fig. $2(\mathrm{a}, \mathrm{b})$. The radiation pattern at $\mathrm{TM}_{02}$ mode is conical also surface current distribution at $\mathrm{TM}_{12}$ mode is bidirectional. In order to reorient the surface currents at $\mathrm{TM}_{02}$ and $\mathrm{TM}_{12}$ mode two horizontal slots are cut on the modified ground plane resulting in pi-shape $(\pi)$ slot formation as seen in Fig. 1 (a). The slot is etched in the location that gives maximum current perturbation (i.e. at $\mathrm{W}_{\mathrm{p} / 4}$ distance from center) at $\mathrm{TM}_{02}$ mode frequency and thus reduces $\mathrm{TM}_{02}$ mode frequency significantly. The effect of varying length of these slots $\left(\mathrm{L}_{\mathrm{r}}\right)$ is studied next and is shown in Fig. 3 (a). The horizontal slots also reorient the current distribution at $\mathrm{TM}_{02}$ mode in horizontal direction and thus broadside radiation pattern is obtained though the current distribution at $\mathrm{TM}_{12}$ mode is still bidirectional. The RMSA with pi-slot on ground plane gives triple band response. The current distribution at various resonant peaks for pi-slot defected ground plane microstrip patch antenna is shown in the Fig. 3 (b-d). 


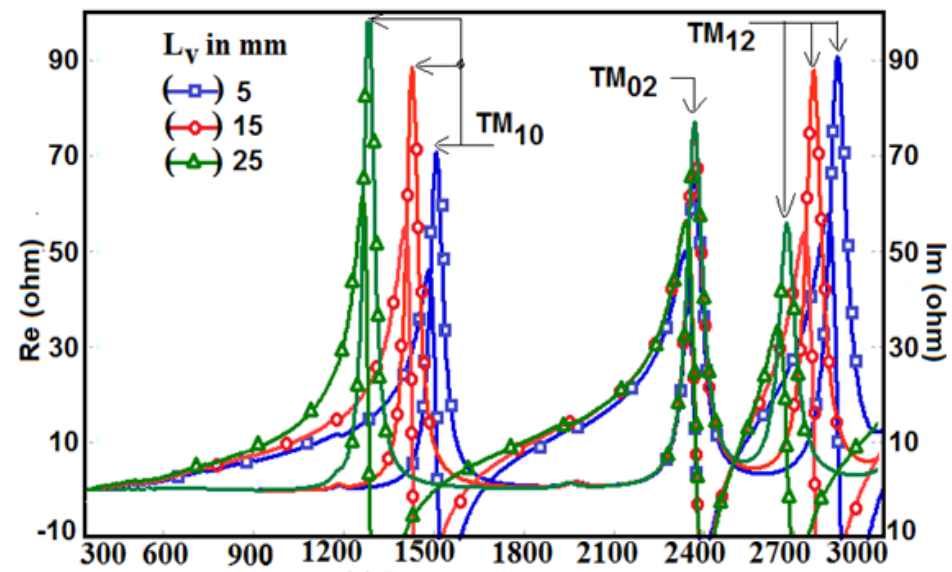

(a) Frequency ( $\mathrm{MHz})$

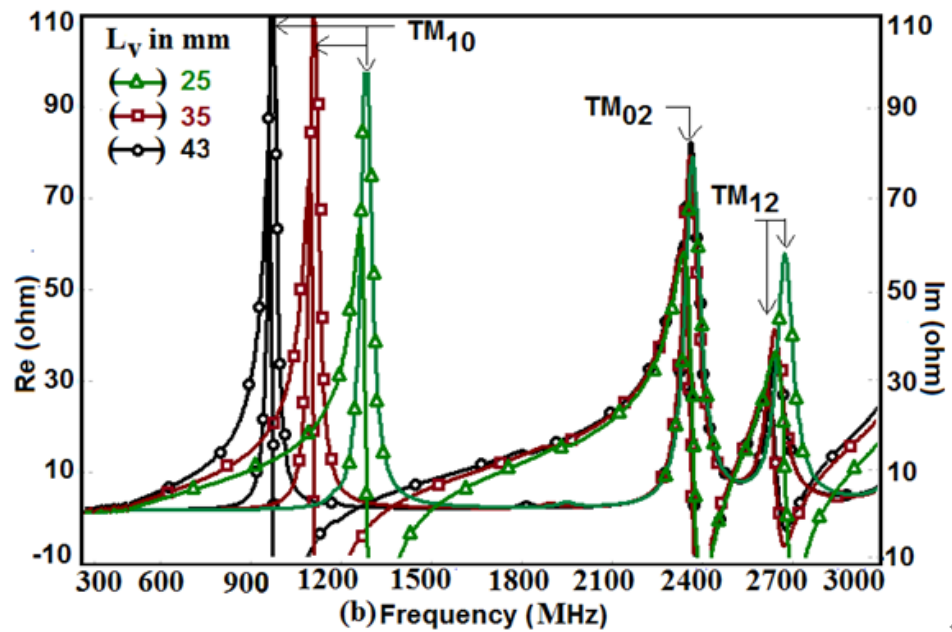

Fig. 2 (a, b) Resonance plot with variations in slot length Lv

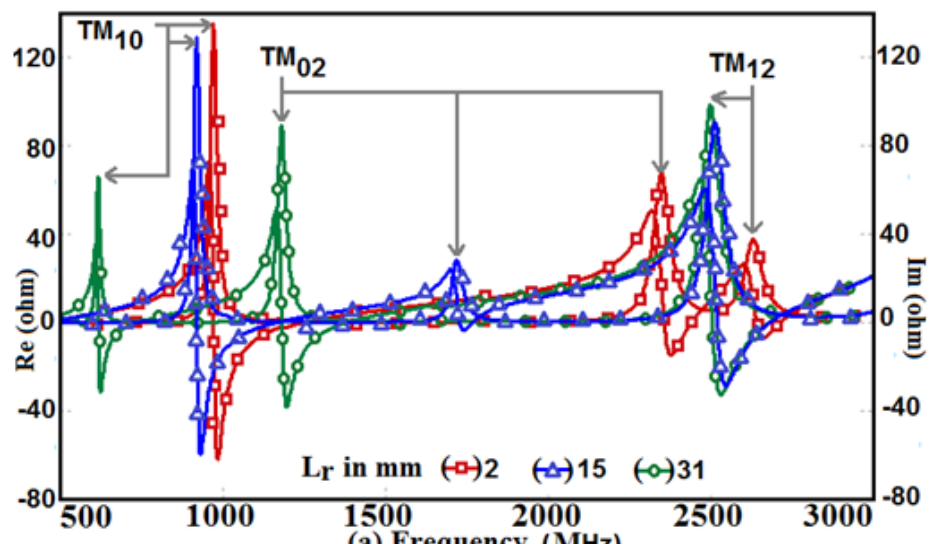

(a) Frequency (MHz) 


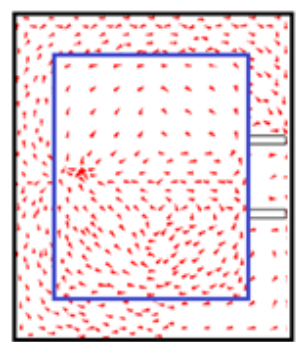

(b) $\mathrm{f}=610 \mathrm{MHz}$

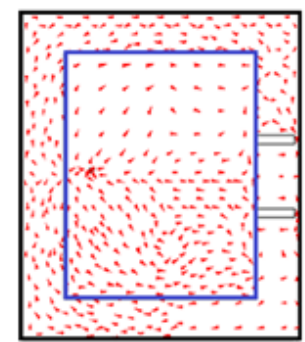

(c) $\mathrm{f}=1180 \mathrm{MHz}$

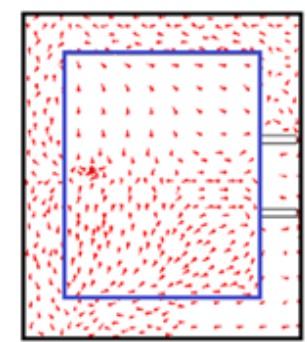

(d) $\mathrm{f}=2500 \mathrm{MHz}$

Fig.3.(a) Resonance plot with variations in Lr, (b-d) Current distribution $\mathrm{Lr}=31 \mathrm{~mm} \mathrm{Lv}=43 \mathrm{~mm}$

The deviation in the position of pi-slot is studied next. The position of the pi-slot is shifted towards left by 4 $\mathrm{mm}$ and the working of the antenna is observed. Same study is later done by shifting pi-slot to $4 \mathrm{~mm}$ right. The resonance plot showing the effect of this shift is shown in Fig. 4 (a). It is observed that shift in right side from origin reduces resonance impedance. Shifting pi-slot by $4 \mathrm{~mm}$ away towards right from origin means moving towards high current location for $\mathrm{TM}_{20}$ mode and thus more perturbation in current leading to reduction in its frequency and hence $\mathrm{TM}_{20}$ frequency comes closer to $\mathrm{TM}_{10}$ mode frequency.

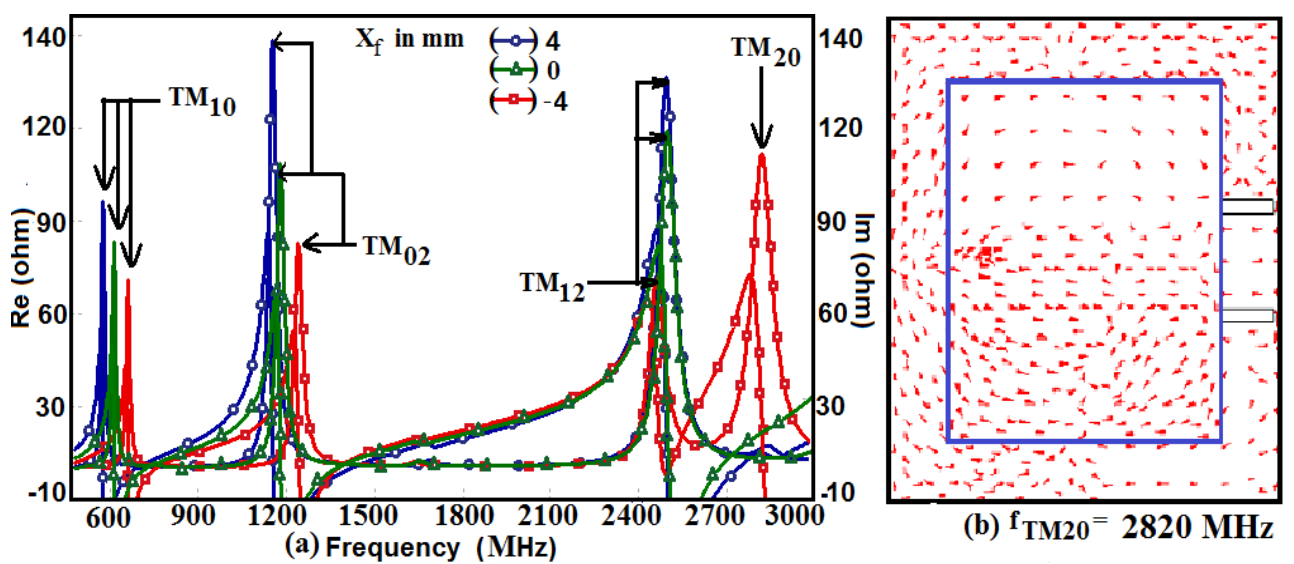

Fig.4. (a) Resonance plot with variation in $\mathrm{X}_{\mathrm{f}}$ (b) current distribution at $\mathrm{f}=2820 \mathrm{MGHz}$ (c) Smith chart for $\mathrm{X}_{\mathrm{f}}$ (feed point location from origin) at $4 \mathrm{~mm}$.

This shift also helps in achieving impedance matching at $\mathrm{TM}_{10}, \mathrm{TM}_{02}$ and $\mathrm{TM}_{12}$ modes. Although impedance matching is achieved in pi-slot RMSA but the pattern at $\mathrm{TM}_{02}$ mode still carry significant amount of cross polar component. Also the current distribution at $\mathrm{TM}_{12}$ mode at $2460 \mathrm{MHz}$ is still bidirectional and large cross polar is observed in the radiation pattern at this mode. Thus two slots $\left(\mathrm{L}_{\mathrm{s} 1}\right)$ are added on the left side of the pi-shape slot thus modifying the pi-shape slot as shown in Fig. 1 (a). The two left arms perturb the current distribution at $\mathrm{TM}_{02}$ mode and helps in achieving current flow along the length of the patch. But the response at $\mathrm{TM}_{12}$ mode still contains cross polar component though less than earlier due to the left arm slots. Also $\mathrm{TM}_{22}$ mode frequency reduces but the pattern at this mode shows conical pattern. The loop is formed inside VSWR 2 circle because of $\mathrm{TM}_{20}$ andTM $\mathrm{TM}_{22}$ modes. Since the loop obtained in the above mentioned configuration was due to coupling between $\mathrm{TM}_{20}$ and $\mathrm{TM}_{22}$ modes and it was seen that the pattern at $\mathrm{TM}_{22}$ mode is conical thus the pattern is not broadside for the complete band. Resonance plot for varying slot length Ls1 is shown in Fig. 5 (a). The optimal value of this length is $13 \mathrm{~mm}$ as further increase in this length reduces impedance at $\mathrm{TM}_{20}$ mode 
frequency significantly. Thus to reduce cross polar component additional pair of slot $\left(\mathrm{L}_{\mathrm{s} 2}\right)$ is added on the left side. These additional slots that are added to the left side suppresses the radiation at $\mathrm{TM}_{22}$ mode as impedance at $\mathrm{TM}_{22}$ reduces on adding these slots. So we get four bands as shown in the resonance plot in Fig. 5 (b) and these resonant peaks are due to $\mathrm{TM}_{10}, \mathrm{TM}_{02}, \mathrm{TM}_{12}$ and $\mathrm{TM}_{20}$ modes. The simulated and measured values of reflection coefficient for this antenna is shown in Fig. 6 (a). In order to achieve broadband response at $\mathrm{TM}_{22}$ mode additional slot $\left(\mathrm{L}_{\mathrm{s} 3}\right)$ along the patch length is introduced. The resulting structure thus comprise of pishape slot with three pair of arms on its left as shown in Fig. 1 (a). These slots $\left(\mathrm{L}_{\mathrm{s} 3}\right)$ which are closer to the edge along with other two left arm slots are responsible to reduce $\mathrm{TM}_{22}$ mode frequency close to $\mathrm{TM}_{20}$ mode frequency and thus collectively gives broadband response.

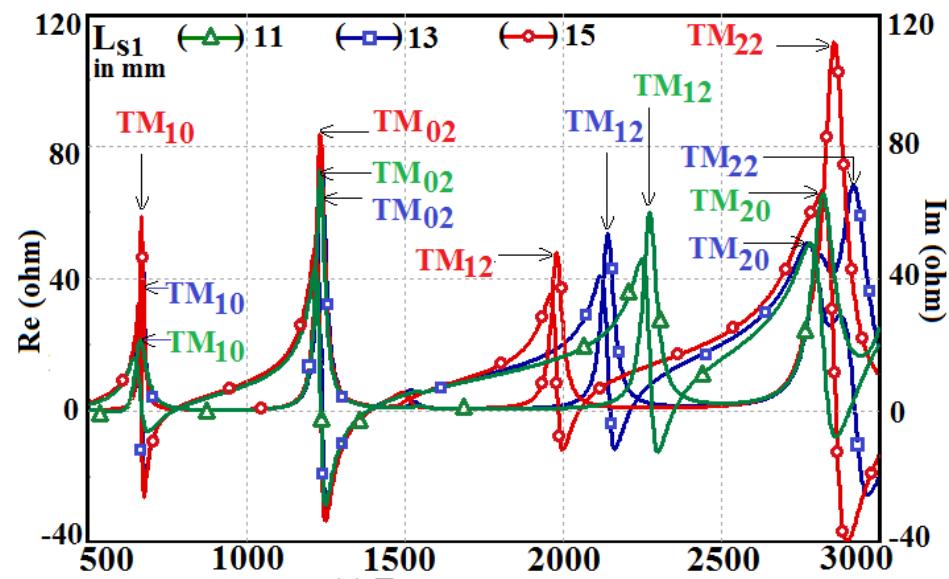

(a) Frequency (MHz)

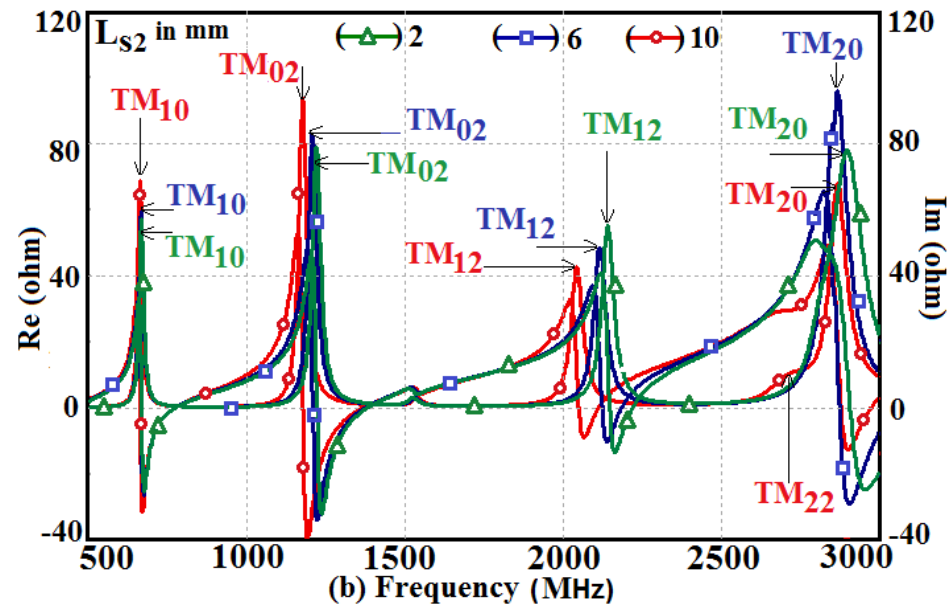

Fig.5. (a) Resonance plot with variations in slot length Ls1 (b) Resonance plot with variations in slot length Ls2 

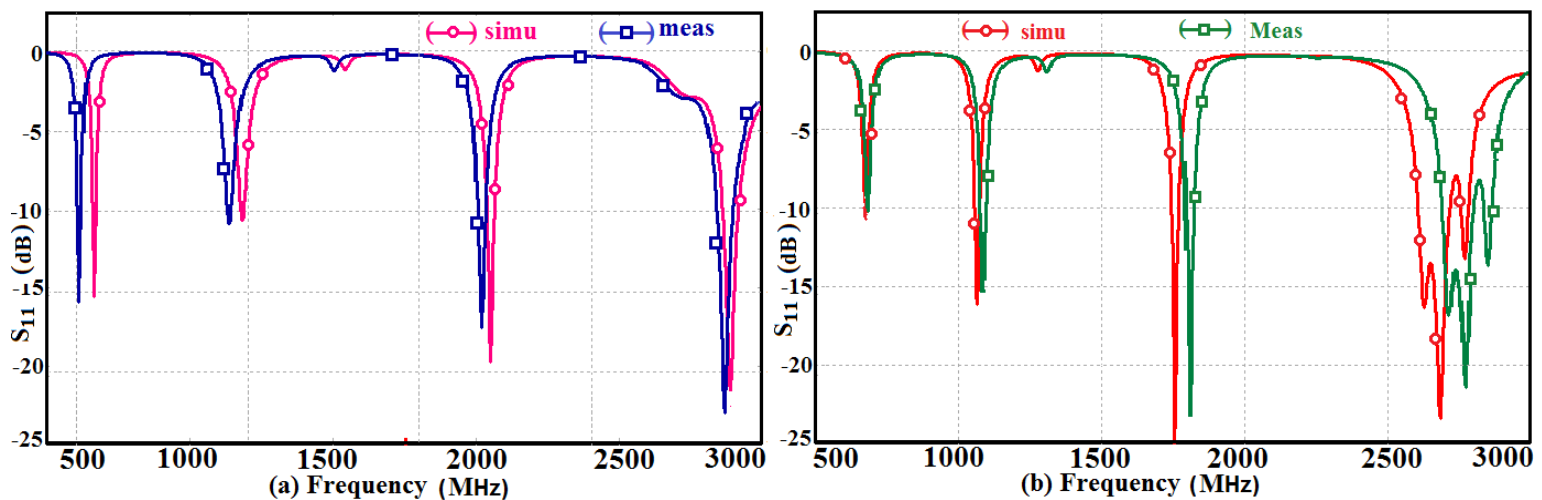

Fig. 6. Simulated and measured Reflection coefficient (a) two left arms (b) proposed antenna with three pairs of arms

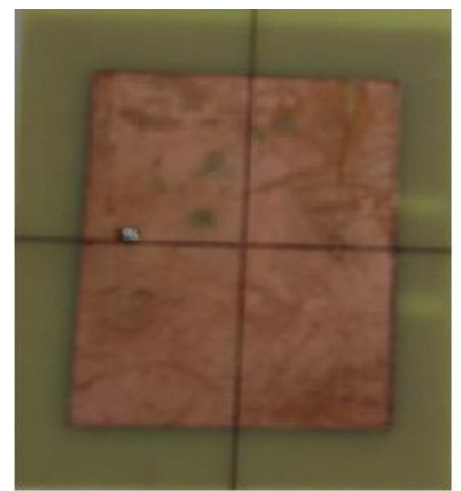

(a)

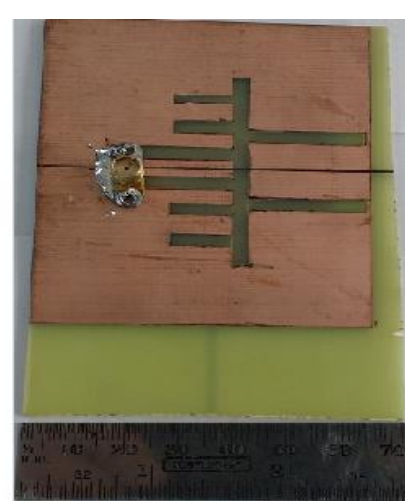

(b)

Fig.7. Fabricated prototype (a) Top view (b) Back view $(\mathrm{Lv}=43 \mathrm{~mm}, \mathrm{Lr}=31 \mathrm{~mm}, \mathrm{Ls} 1=13 \mathrm{~mm}, \mathrm{Ls} 2=\mathrm{Ls} 3=10 \mathrm{~mm})$

The fabricated antenna is operating on multiple bands at the frequencies close to the simulated frequencies. Since more than five bands are obtained thus for clarity reflection coefficient plot is shown in Fig. 6 (b). The reflection coefficient at each mode is less than $-10 \mathrm{~dB}$ thus ensuring less power loss at the input of antenna. The simulated and measured radiation pattern at each mode is shown in Fig. $8(\mathrm{a}-\mathrm{h})$. The simulated fequencies are $678,1060,1750,2670$ and $2760 \mathrm{MHz}$. The patch was fabricated and the multiband response was experimentally verified. The measured center frequencies are 6708, 1080, 1770, 2670 and $2740 \mathrm{MHz}$. The wide bandwidth obtained is $164 \mathrm{MHz}(6.5 \%)$ while the other three bands has bandwith of $6 \mathrm{MHz}(1 \%), 18 \mathrm{MHz}$ $(1.7 \%)$ and $29 \mathrm{GHz}(1.6 \%)$. The top view and back view of the fabricated prototype of the proposed antenna is shown in Fig. 7 (a, b). 


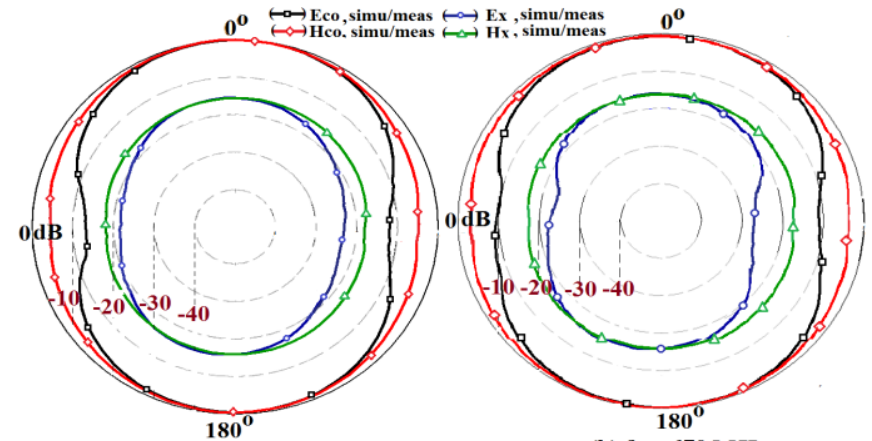

(a) $f=678 \mathrm{MHz}$, simu

(b) $\mathrm{f}=670 \mathrm{MHz}$, meas
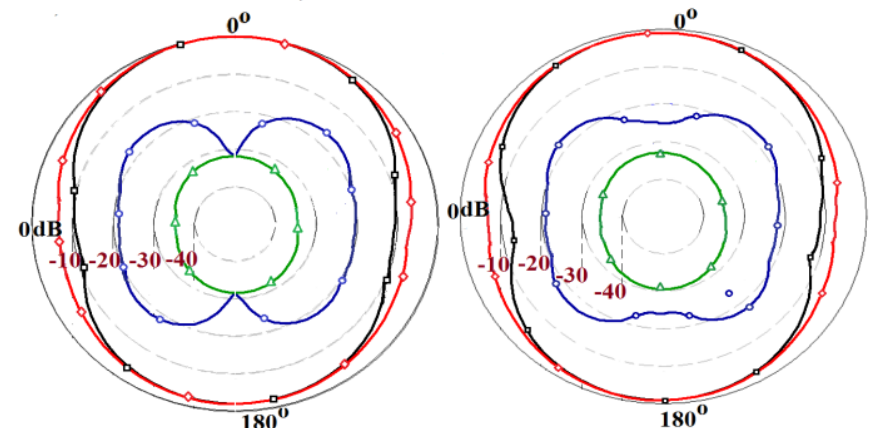

(c) $f=1060 \mathrm{MHz}$, simu

(d) $\mathrm{f}=1080 \mathrm{MHz}$, meas
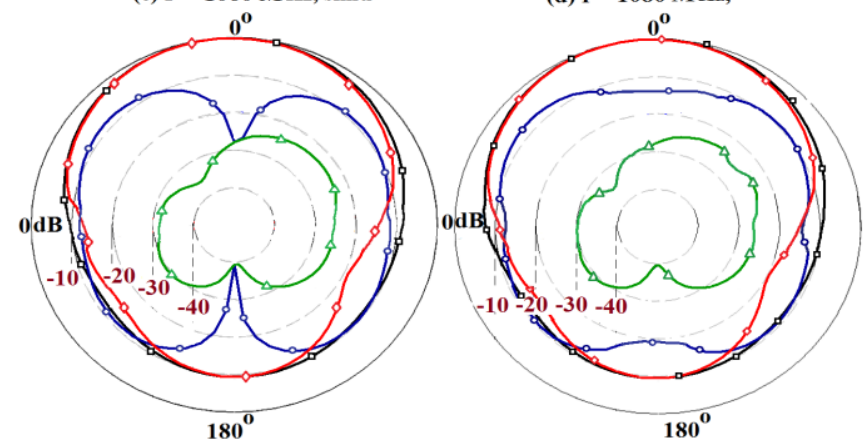

(e) $\mathrm{f}=1750 \mathrm{MHz}, \operatorname{simu}$

(f) $f=1770 \mathrm{MHz}$, meas

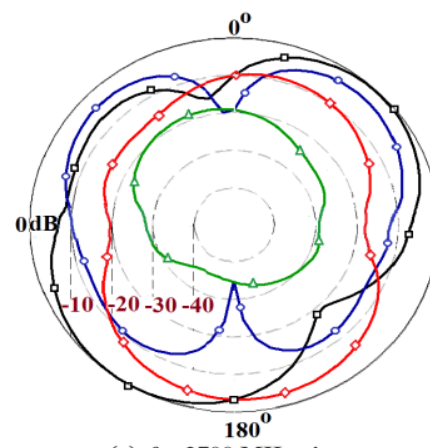

(g) $f=2700 \mathrm{MHz}, \operatorname{simu}$

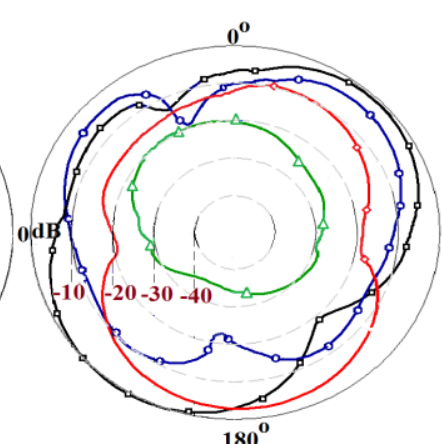

(h) $\mathrm{f}=2700 \mathrm{MHz}$, meas

Fig.8. (a-h) Simulated and measured radiation pattern for MSA with modified pi slot on the ground plane 


\section{Suspended Modified Pi-Slot Defected Ground RMSA}

The gain of the antenna is improved by introducing multiple layers of dielectric substrates thereby converting it into three layer structure. Fig 9 (a) and Fig 9 (b) shows the proposed antenna configuration and the side view respectively. Air gap of $1.6 \mathrm{~mm}$ between two glass epoxy substrates of thickness $1.6 \mathrm{~mm}$ each results in total height of $4.8 \mathrm{~mm}$. The equivalent dielectric constant of the antenna is also reduced due to this stacking and is computed using equation (1).

$$
\varepsilon_{\mathrm{eq}}=\frac{\varepsilon_{\mathrm{r}}(2 \mathrm{~h}+\Delta)}{2 \mathrm{~h}+\Delta \varepsilon_{\mathrm{r}}}
$$

The effective dielectric constant is calculated using equation (II).

$$
\varepsilon_{\mathrm{re}}=\frac{\varepsilon_{\mathrm{eq}}+1}{2}+\frac{\varepsilon_{\mathrm{eq}}-1}{2} / \sqrt{\left(1+\frac{10 \mathrm{~h}}{\mathrm{w}}\right.}
$$

In the above expressions, $\mathrm{h}$ is the thickness of glass epoxy substrate, $\Delta$ is the air gap, and $\mathrm{w}$ is the width of the patch. The equivalent dielectric constant of the antenna from equation (1) is 1.938. The patch dimension is then calculated considering the effective dielectric constant. Patch length and width taken here is $64 \mathrm{~mm}$ and 77 $\mathrm{mm}$ respectively. And the ground plane dimension is $84 \mathrm{~mm}$ x $97 \mathrm{~mm}$. This structure yields triple band response and offers broadside gain of around $4 \mathrm{dBi}$ at the broadband besides $2.5 \mathrm{dBi}$ and $1 \mathrm{dBi}$ gain at other two modes. The analysis of suspended configuration is carried out in the similar line like the non- suspended antenna. The equivalent suspended configuration without slots was studied first to identify the resonant modes that were excited when the feed was placed at the given location. Four resonant peaks are observed at $\mathrm{f}_{10}=$ $1450 \mathrm{MHz}, \mathrm{f}_{02}=2410 \mathrm{MHz}, \mathrm{f}_{12}=2880 \mathrm{MHz}$ and $\mathrm{f}_{22}=3900 \mathrm{MHz}$ frequencies when slots are not incorporated in the suspended RMSA structure. These resonant modes obtained are due to $\mathrm{TM}_{10}, \mathrm{TM}_{02}, \mathrm{TM}_{12}$ and $\mathrm{TM}_{20}$ modes respectively. The loss tangent of the antenna reduces in suspended configuration and hence it is observed that the impedances over the resonance peak gets modified with respect to the non-suspended configuration. Thus some modifications are incorporated in the suspended configuration in order to obtain multiband response which would have not been possible with the previous structure.

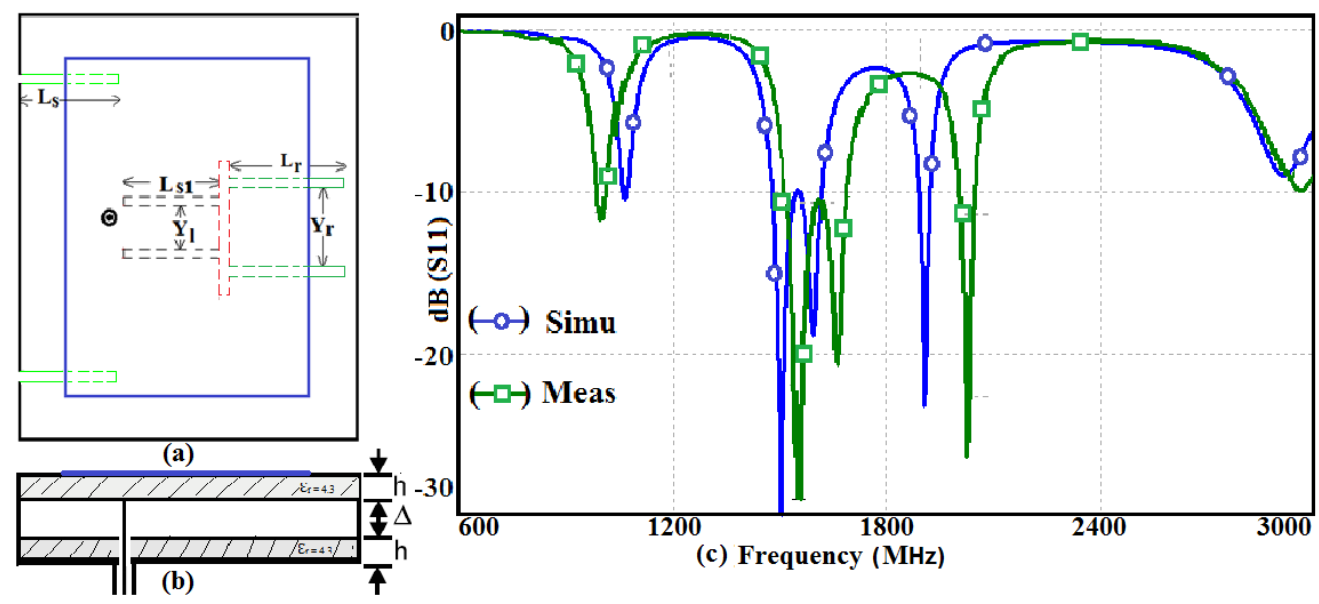

Fig.9. (a) Three layer Suspended RMSA with Pi-slot on ground (b) side view (c) $\mathrm{S}_{11}$ plot 


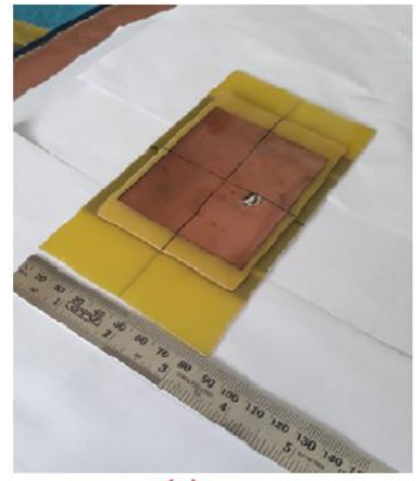

(a)

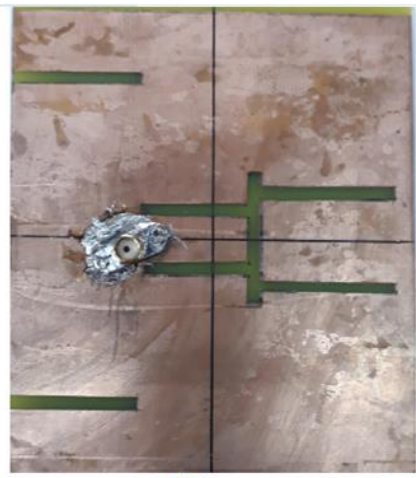

(b)

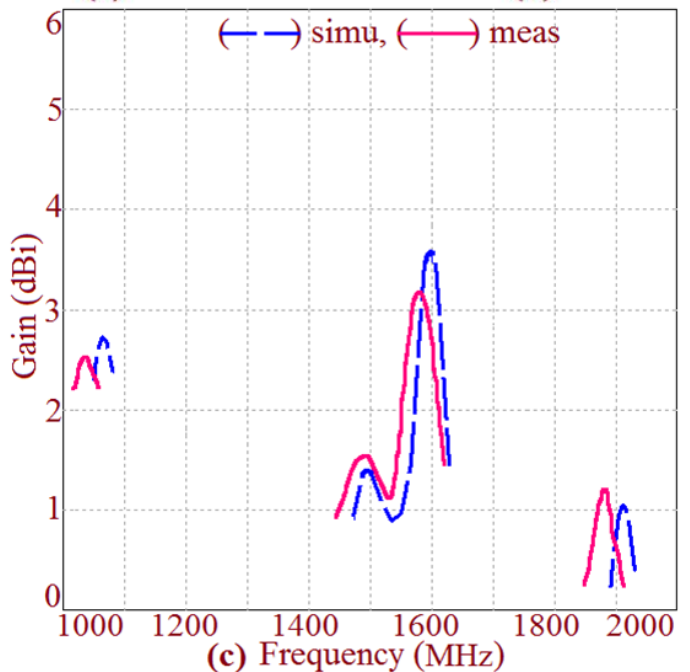

Fig.10. Fabricated prototype of the proposed antenna (a) Top view (b) Back view (c) Gain versus frequency plot of proposed antenna

As mentioned earlier similar study is done in the suspended configuration, so a vertical slot is incorporated at the origin. The effect of variation in slot length $(\mathrm{Lv})$ is studied .The effect of the vertical slot is seen on frequency as well as impedance. Increase in vertical slot at center reduces $\mathrm{TM}_{10}$ mode frequency thus yields compactness. This slot also reduces $\mathrm{TM}_{12}$ mode frequency as shown in resonance overlap plot. The slot results in frequency reduction but increases the impedance by significant amount. Therefore to achieve impedance matching at this mode the vertical slot is shifted $10 \mathrm{~mm}$ away from the center. But the pattern is not broadside at all the modes. Thus a pair of horizontal slot is added to the right of the vertical slot giving it a pi-shape. It is observed that the current distribution even after adding horizontal slots on right is not unipolar at each mode. The current distribution at $\mathrm{TM}_{02}$ and $\mathrm{TM}_{22}$ modes are not unipolar and thus horizontal slots are added on left side as well. Also in order to further improve the cross polar reduction two slots are added on the ground plane making it E-shape ground plane. This helps to achieve unipolar current distribution and thus multiband. The effect of variation in slot length $\left(\mathrm{L}_{\mathrm{s}}\right)$ is studied and the optimum loop is formed inside VSWR $=2$ circle for slot length $\left(\mathrm{L}_{\mathrm{s}}\right)$ equal to $26 \mathrm{~mm}$.

The simulated frequencies are 1040, 1460, 1570, $1880 \mathrm{GHz}$ and there BW's are $18 \mathrm{MHz}, 142 \mathrm{MHz}$ and 35 MHz respectively. The proposed antenna prototype is shown in Fig. 10 (a, b). The fabricated patch yield multiband response which was experimentally verified. The experimentally measured center frequencies for the three bands are 1140, 1529, $1992 \mathrm{GHz}$ and there BW's are $18 \mathrm{MHz}(1.7 \%), 158 \mathrm{MHz}(10 \%)$ and $30 \mathrm{MHz}$ 
$(1.6 \%)$ respectively. The frequency tuning between the modes can be easily obtained by changing the slot dimensions. The center frequency ratio with respect to the first band f2/f1 (2nd band and 1st band). The resonant peaks observed are due to $\mathrm{TM}_{10}, \mathrm{TM}_{12}, \mathrm{TM}_{20}$ and $\mathrm{TM}_{22}$ modes respectively. The center frequency ratio with respect to the first band f2/f1 (2nd band and 1st band) is 1.3 and f3/f1 (3rd band and 1st band) is 1.7. The gain of the antenna is in range $1 \mathrm{dBi}-4 \mathrm{dBi}$ as shown in Fig. 11(c). The radiation pattern observed at each of the frequencies. Thus, this paper provides a detailed explanation of effects of slots on the ground plane and gives a systematic design procedure to yield multiband /broadband response with modified ground plane structure.

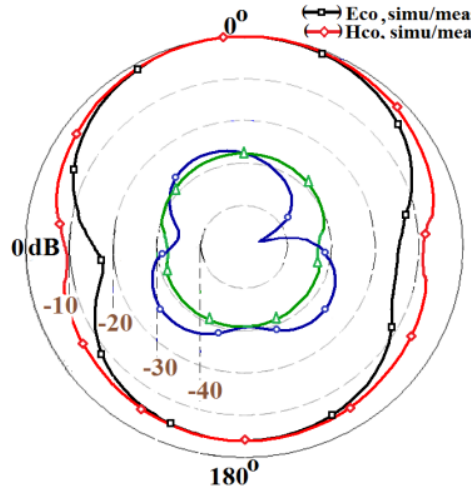

(a) $\mathbf{f}=1040 \mathrm{MHz}, \operatorname{simu}$

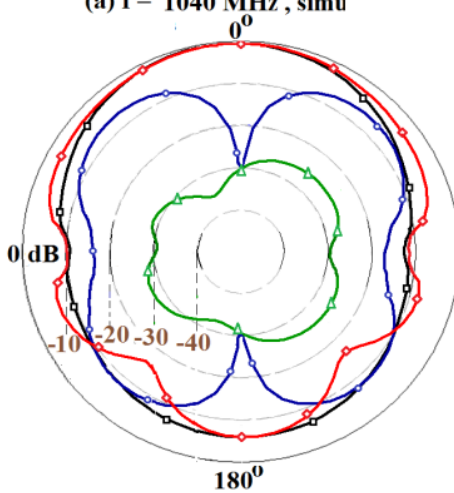

(c) $\mathbf{f}=1520 \mathrm{MHz}, \operatorname{simu}$

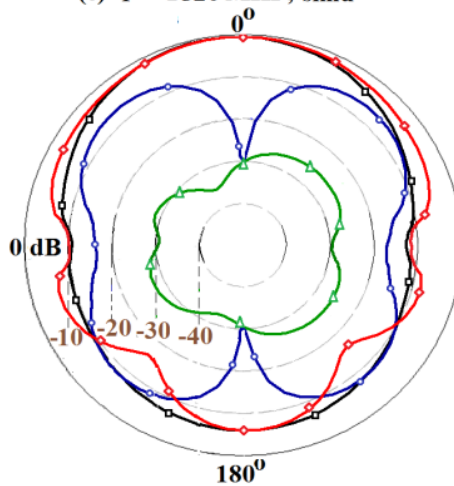

(e) $\mathrm{f}=1880 \mathrm{MHz}$, simu

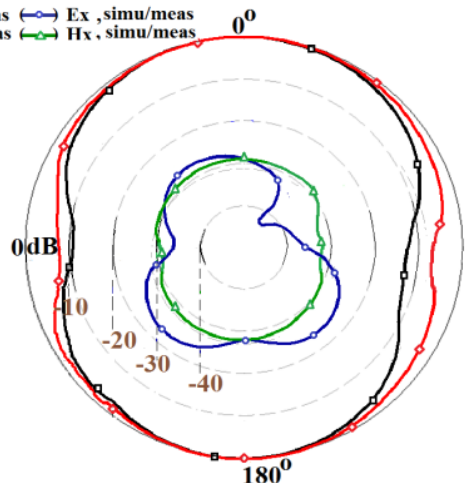

(b) $f=1140 \mathrm{MHz}$, meas

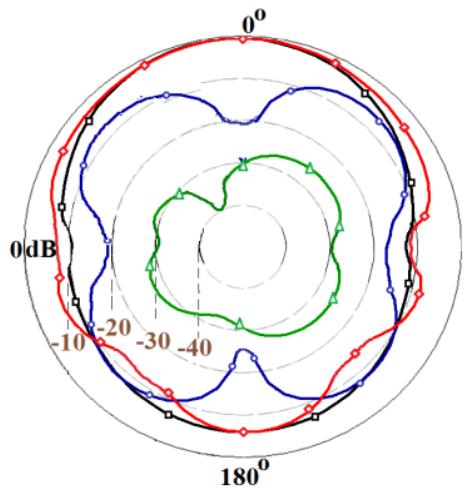

(d) $f=1529 \mathrm{MHz}$, meas

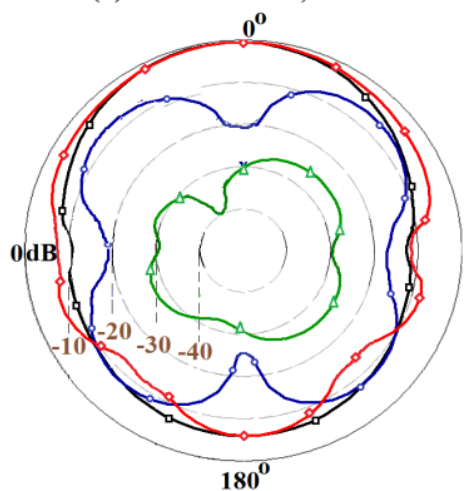

(f) $f=1992 \mathrm{MHz}$, meas

Fig.11. (a-f) Simulated and measured radiation pattern for Suspended MSA with modified pi slot on ground plane 


\section{Conclusions}

A multiband defected ground microstrip antenna with modified pi-slot is designed and modal behavior is explained. Also pi-slot DGS RMSA is designed on a suspended dielectric substrate with coaxial feed to enhance the gain of the antenna which realizes multiband response at the center frequencies 1140, 1529 and $1992 \mathrm{GHz}$ with broadband bandwidth of $158 \mathrm{MHz}(9.3 \%)$ at one of the band. Maximum broad band gain obtained is around $4 \mathrm{dBi}$. The multiband responses observed in the proposed antenna are due to the $\mathrm{TM}_{10}, \mathrm{TM}_{20}$ and $\mathrm{TM}_{20}$ modes of RMSA. The radiation pattern is in the broadside direction at all the peaks with $\mathrm{E}$ and $\mathrm{H}$ planes aligned along $\Phi=0^{\circ}$ and $90^{\circ}$, respectively. All the antennas in the paper are fabricated and tested. The simulated and measured values closely match to the each other.

\section{References}

[1] Girish kumar, K. P.Ray, "Broadband Microstrip Antenna”, Artech House, Boston, 2003.

[2] Amit A. Deshmukh and K. P. Ray,"Multi band configurations of stub loaded slotted rectangular microstrip antennas" IEEE Antennas and Propagation Magazine, Vol. 52, No.1, February 2010.

[3] Amit A. Deshmukh, A. A. Kadam and K. P. Ray," Analysis of slot cut broadband and dual band rectangular Microstrip Antenna", IETE Journal of research, May 2013.

[4] H. F. Abu Tarboush, H. S. Al-Raweshidy and R. Nilavalan, "Multi-Band Antenna for different wireless Applications", IEEE Interational workshop on Antenna Technology, 978-1-4244-4396-3/09, March 2009.

[5] K. F. Tong, K. M. Luk, K. F. Lee and R. Q. Lee, "A Broadband U-slot Rectangular Patch Antenna on a Microwave Substrate", IEEE Transactions on Antennas \& Propagation, vol. 48, pp. 954 -960, June 2000.

[6] Kin Lu Wong and Kai Ping "Compact dual-frequency microstrip antenna with a pair of bent slots, Electronics Letters, Vol. 34, February 1998.

[7] G. F. Khodaei, J. Nourinia and C. Ghobadi, "A Practical Miniaturized U-slot Patch Antenna with Enhanced Bandwidth", Progress In Electromagnetic Research B, vol.3, pp.47 - 62, 2008.

[8] A. A. Deshmukh and G. Kumar, "Compact Broadband U-slot loaded Rectangular Microstrip Antennas", Microwave and Optical Technology Letters, vol. 46, no. 6, pp. 556 - 559, September 2005.

[9] K. L. Wong, "Compact and Broadband Microstrip Antennas", John Wiley \& sons, Inc., New, USA, 2002.

[10] Prabhakar H. V., U. K. Kummuri, R. M. Yadahalli and V. Munnappa, "Effect of various meandering slots in rectangular microstrip Antenna ground plane for compact broadband operation", Elextronics Letters, Vol. 43, August 2007.

[11] Jieh-Sen Kuo and Kin-Lu Wong, "A compact microstrip antenna with meandering slots in the ground plane", Microwave and optical technology letters, Vol. 29, April 2001.

[12] M. Chakraborty, B. Rana, P. P. Sarkar \& Achintya Das, "Design and Analysis of a compact rectangular micrrostrip antenna with slots using Defective ground structure", Elsevier Procedia technology, 2012.

[13] Hanae Elftouh, Naima A. Touhami, Mohamed Aghoutane, Safae E. Amrani, Antonio Tazon, and Mohamed Boussouis, "Miniaturized Microstrip Patch Antenna with Defected Ground Structure", Progress In Electromagnetics Research, Vol. 55, 2014.

[14] Mukesh Kumar Khandelwal, Binod Kumar, Shantanu Dwari, Sachin Kumar and A. K. Gautam, "Compact stacked Microstrip patch antenna with defected ground structure for WLAN/ WiMax applications", AEUInternational journal of Electronics and Communications, Volume 69, pages 39-47, January 2015.

[15] Amandeep Singh, Surinder Singh, "A novel CPW-fed wideband printed monopole antenna with DGS", AEU- International journal of Electronics and Communications, Volume 69, pages 299-306, January 2015. 


\section{Authors' Profiles}

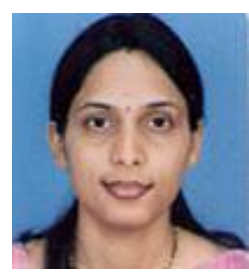

Poonam A. Kadam has completed her B.E. (Electronics) from S.G.G.S Institute of Engineering and Technology, Nanded in June 2001 and M.Tech (Electronics Engineering) from I.I.T BHU, in Jan 2003. At present is working as Assistant professor in Department of Electronics and Telecommunication Engineering at D. J. Sanghvi College of Engineering, Mumbai. Currently pursuing Doctoral program in Telecommunication Engineering from research Centre of Department of Electronics and Telecommunication Engineering of D. J. Sanghvi College of Engineering, University of Mumbai.

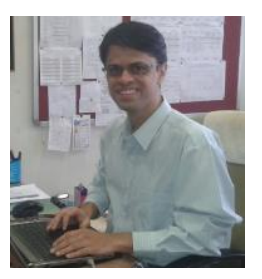

Amit A. Deshmukh obtained B.E. (Electronics) from V.I.T., Pune University in 1997. He obtained M.Tech. Degree in 2000 and Ph. D. in 2004 from Department of Electrical Engineering, I. I. T. Bombay. His thesis work during masters and doctoral, was on Compact broadband and dual band microstrip antennas. He is working as Professor \& Head of the Department of Electronics and Telecommunication Engineering at D. J. Sanghvi College of Engineering, Vile - Parle (W), Mumbai, India. He has together (Teaching, Industry, and Research) more than 17 years of experience. He has published more than 220 research papers in various International and National Journals and Conferences. He is on reviewer list of many International Journals like, IEEE Magazine on Antennas and Propagation, IEEE Transaction of Antennas and Propagation, IEEE Antennas and Wireless Propagation Letters, IET Microwave Antennas and Propagation, PIERS journals, International Journal of Electronics, IETE Journal of Research, Elsevier Electronics and Communication Journal. He has delivered many lecture talks in National/International conferences and workshops in the areas of patch antennas.

How to cite this paper: Poonam A. Kadam, Amit A. Deshmukh, "Multiband Microstrip Antenna Using Modified Pi-Shape Slot on Ground Plane", International Journal of Wireless and Microwave Technologies(IJWMT), Vol.9, No.1, pp. 23-35, 2019.DOI: 10.5815/ijwmt.2019.01.03 